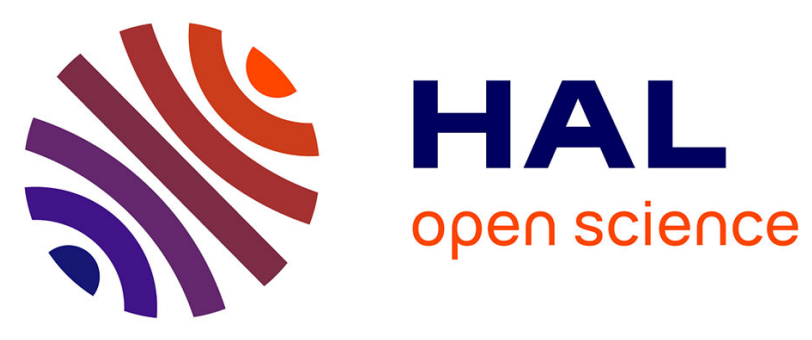

\title{
Total phosphorus determination in Eutrophic Tropical River Sediments by Laser-Induced Breakdown Spectroscopy techniques
}

Carla Pereira de Morais, Gustavo Nicolodelli, Milene Corso Mitsuyuki, Kleydson Stênio Gaioso da Silva, Frederico Fábio Mauad, Stéphane Mounier, Debora Marcondes Bastos Pereira Milori

\section{To cite this version:}

Carla Pereira de Morais, Gustavo Nicolodelli, Milene Corso Mitsuyuki, Kleydson Stênio Gaioso da Silva, Frederico Fábio Mauad, et al.. Total phosphorus determination in Eutrophic Tropical River Sediments by Laser-Induced Breakdown Spectroscopy techniques. Analytical Methods, 2021, 13 (1), pp.77-83. 10.1039/D0AY02008G . hal-03130783

\section{HAL Id: hal-03130783 https://hal.science/hal-03130783}

Submitted on 3 Feb 2021

HAL is a multi-disciplinary open access archive for the deposit and dissemination of scientific research documents, whether they are published or not. The documents may come from teaching and research institutions in France or abroad, or from public or private research centers.
L'archive ouverte pluridisciplinaire HAL, est destinée au dépôt et à la diffusion de documents scientifiques de niveau recherche, publiés ou non, émanant des établissements d'enseignement et de recherche français ou étrangers, des laboratoires publics ou privés. 


\title{
Total phosphorus determination in Eutrophic Tropical River Sediments by Laser-Induced Breakdown Spectroscopy techniques
}

\author{
Carla Pereira de Morais, ${ }^{a}$ Gustavo Nicolodelli, ${ }^{b}$ Milene Corso Mitsuyuki, ${ }^{c}$ Kleydson Stênio Gaioso da Silva, ' Frederico Fábio Mauad, ${ }^{\mathrm{d}}$ \\ Stéphane Mounier ${ }^{\mathrm{e}}$ and Débora Marcondes Bastos Pereira Milori *c
}

Total phosphorus (TP) in sediments is an important chemical variable in the study of the extent of eutrophication in water bodies. Two methods, based on Single Pulse (SP) and Double Pulse (DP) Laser-Induced Breakdown Spectroscopy (LIBS), were developed for determining TP in the sediment cores of Brazilian rivers upstream from the Barra Bonita reservoir. TP concentration in the sediments was determined by inductively coupled plasma optical emission spectrometry (ICP OES) on digested samples. Besides, a LIBS system operating in SP and DP mode was used to develop methods for the TP quantification in sediment pellets. In LIBS, the most appropriate wavelength to measure $P$ was at $214.91 \mathrm{~nm}$. The calibration curves showed correlation coefficients of 0.93 and 0.92 , limits of detection of $709 \mathrm{mg}$ $\mathrm{kg}-1$ and $349 \mathrm{mg} \mathrm{kg-1}$ for SP and DP LIBS, respectively. The two proposed methods were validated and presented an average percentage error of $14 \%$ and $10 \%$ for SP and DP LIBS, respectively. The ICP OES, SP and DP LIBS data showed that the most superficial layers of the Piracicaba river, all the sedimentary layers of the Tietê river, and the confluence region present a high concentration of TP, according to Brazilian sediment quality criterion. In conclusion, SP and DP LIBS were confirmed as promising alternative tools to traditional analytical methods for monitoring the TP content in the sediments that come from different hydrographic units. The proposed method using DP LIBS proved more sensitive than SP LIBS, but the SP LIBS method demonstrated enough precision for determining TP in eutrophic river sediments.

\section{Introduction}

The origin of $P$ in sediments can be natural, coming from outside the aquatic system (allochthonous) or from within the system (autochthonous), and anthropogenic ${ }^{1}$ Depending on the concentrations, $\mathrm{P}$ can be harmful to the aquatic system, accelerating the eutrophication process of rivers. ${ }^{2,3}$ The most severe environmental consequence is the decrease in dissolved oxygen in the water, causing the death of plant and animal species. Also, it changes the taste and smell of water. ${ }^{4}$

Total phosphorus (TP) is an important chemical variable in the study of sediment quality, as it assesses the nutrient load and the extent of the degree of eutrophication of water bodies. The chemical analysis of sediment cores is used to evaluate the distribution of the elements in-depth and correlate the profile obtained with the history of land use and occupation and, consequently, with potential anthropic contributions. These conditions are not always detectable using water variables. The official method for determining TP in sediments is the USEPA 6010C Method. ${ }^{5}$ This method uses inductively coupled plasma optical emission spectrometry (ICP OES) for determination and requires treatment of samples, such as wet decomposition using high volumes of oxidizing mixtures. ${ }^{4,6,7}$ Thus, generating considerable amounts of chemical residues, disagreeing with the principles of Green Chemistry. ${ }^{8}$

Laser-Induced Breakdown Spectroscopy (LIBS) is an alternative to the disadvantages associated with sample preparation, as it provides direct analysis, thus eliminating or reducing the use of chemical reagents. Besides, the LIBS technique has other advantages, such as relatively low analyses cost when compared to conventional analytical methods, and fast real-time analysis. LIBS is an optical emission spectroscopy technique that uses a laser-generated plasma to vaporize, atomize and excite analytes. When excited species return to a lower energy state, they emit discrete emission lines that are characteristic of each element. ${ }^{9}$ This emission spectrum contains qualitative and quantitative information on the sample composition. ${ }^{10}$ Due to the matrix effect, quantitative analysis and increased sensitivity are still analytical challenges to be overcome. ${ }^{11}$ The Double Pulse (DP) LIBS approach has demonstrated a significant increase in sensitivity when compared with the Single Pulse (SP) LIBS. ${ }^{12-14}$

Although the LIBS technique has shown potential for elementary analysis in marine ${ }^{15,16}$ and river sediments, ${ }^{17}$ there is no study on the application of SP and DP LIBS techniques combined with ICP OES to assess the quality of river sediments concerning the TP concentration. This lack of LIBS work in the literature is due to the challenge of constructing calibration models for samples with significant variation in their physic-chemical characteristics, as can be seen in sediments that receive sewage runoff, and industrial activities. ${ }^{18}$ This work aims to develop methods using SP and DP LIBS techniques to assess the quality of river sediments from different hydrographic units, which receive different effluent loads, concerning the TP distribution in different sediment core depths.

\section{Experimental}

\subsection{Collection and preparation of samples}

Sediment samples were collected in the Tietê and Piracicaba rivers, from their input compartments in the Barra Bonita reservoir, São Paulo state, Brazil (Fig. 1), ${ }^{19}$ on the 25th of July of 2017, from three points on the Tietê river, three points on the Piracicaba river, and one point in the confluence region.

The average water depth upstream of the reservoir is $10.2 \mathrm{~m}$. The sediment cores were taken at different depths using core sampling. The collection points were georeferenced using the Trimble Navigator GPS (Table S1). Each river belongs to a water resource management unit, with different types of land use and occupation. The Tietê river is the most polluted in Brazil and practically crosses 
the entire state of São Paulo passing through the Metropolitan Region of São Paulo City. The Piracicaba river is the largest tributary in terms of the water volume of the Tietê river. ${ }^{20}$

The transversal slicing was done in different sizes (Table S2) along the seven cores without removing interstitial water-sediment, totaling 69 sample layers. All samples collected were placed in plastic containers and stored in a thermal box during transport to the laboratory. The samples were freeze-dried (L101, Liotop), ground using a mortar grinder (RM 200, Retsch), and sieved through a 100-mesh sieve. For SP and DP LIBS analyses, an aliquot of $500 \mathrm{mg}$ of each sample was converted into pellets by applying 5 tons of pressure for $1 \mathrm{~min}$ in a hydraulic press.

\subsection{Emission spectrometry analyses}

ICP OES was the reference technique for determining the P concentration for all the samples. It used an iCAP 6000 ICP OES (Thermo Fisher Scientific) with an axial view, radio frequency (RF) generator of $1.55 \mathrm{~kW}$, echelle polychromator with continuous wavelength coverage in the range of $166.4 \mathrm{~nm}$ to $847.0 \mathrm{~nm}$, and a high-performance solid-state detector with CID86 chip. Argon gas (99.996\%, White Martins-Praxair) was used in all the measurements. The $P$ line at $178.2 \mathrm{~nm}$ was monitored in optimized plasma operating conditions (Table 1 ).

Table 1 Operating conditions for ICP OES determinations.

\begin{tabular}{cc}
\hline Instrument parameter & Operating condition \\
\hline $\begin{array}{c}\text { Integration time }(\mathrm{s}) \\
\text { Sample introduction flow rate } \\
\left(\mathrm{mL} \mathrm{min}^{-1}\right)\end{array}$ & 15.0 \\
Pump stabilization time $(\mathrm{s})$ & 1.00 \\
$\mathrm{RF}$ applied power $(\mathrm{kW})$ & 5 \\
Auxiliary gas flow rate $\left(\mathrm{L} \mathrm{min}^{-1}\right)$ & 0.50 \\
Carrier gas flow rate $\left(\mathrm{L} \mathrm{min}^{-1}\right)$ & 0.50 \\
Plasma gas flow rate $\left(\mathrm{L} \mathrm{min}^{-1}\right)$ & 12 \\
Nebulizer & V-Goove \\
Spray chamber & Cyclonic \\
\hline
\end{tabular}

The ICP OES analyses were conducted on digested samples. The decomposition procedure is described below: $200 \mathrm{mg}$ of each homogenized sample was accurately weighed and transferred to the Perfluoro alkoxy (PFA) decomposition flasks with $10.0 \mathrm{~mL}$ of $\mathrm{HNO}_{3}$ (Synth) purified in a sub-boiling distillation system Distillacid ${ }^{\mathrm{TM}}$ BSB-939-IR (Berghof, Eningen). Then, this solution was digested using a microwave oven (Speedwave four, Berghof, Eningen) in triplicate. The microwave oven heating program used consisted of (i) $5 \mathrm{~min}$ to reach $120^{\circ} \mathrm{C}$, (ii) remained at that temperature for $5 \mathrm{~min}$, (iii) 5 min to reach $175^{\circ} \mathrm{C}$, and (iv) remained at that temperature for $10 \mathrm{~min}$. The maximum temperature of the flasks was approximately $175^{\circ} \mathrm{C}$, and the time for complete digestion was 25 minutes. The tubes were cooled to room temperature in a fume hood. An analytical blank accompanied all procedures. After digesting and cooling, the samples and analytical blanks were transferred to $50.0 \mathrm{~mL}$ volumetric flasks, and the volume was completed with deionized water. Subsequently, the digests were diluted 2.5 times with deionized water so that the acid concentration would remain in the equipment's standards. The accuracy of the reference method was evaluated using certified reference materials (CRMs) Montana II Soil (SRM 2711a), and San Joaquin Soil (SRM 2709a). 


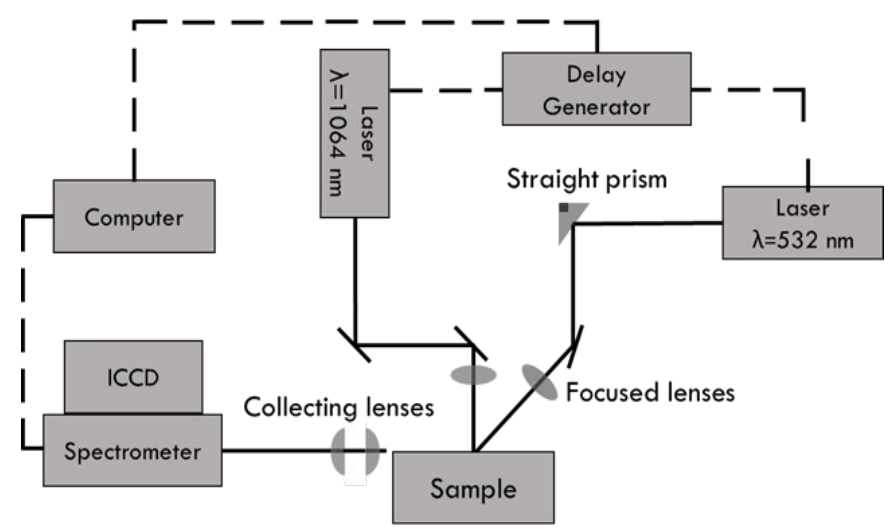

Fig. 2 Scheme of the LIBS setup.

\subsection{LIBS setup}

A cross beam double pulse LIBS system was developed to analyze sediments. It was composed of two Nd:YAG pulsed lasers operating at different wavelengths, $1064 \mathrm{~nm}$ and $532 \mathrm{~nm}$ (Fig. 2). A delay generator pulse was used for the temporal control between the two lasers and the data acquisition system. An echelle spectrometer equipped with an intensified coupled charge device (ICCD) with $1024 \times 1024$ pixels was used to obtain the spectra. The spectrometer operated in two spectral bands, 175-330 $\mathrm{nm}$, and $275-750 \mathrm{~nm}$, with a resolution of $13-24 \mathrm{pm}$, and $29-80 \mathrm{pm}$, respectively.

The laser that emits in $1064 \mathrm{~nm}$ (Q-switched Ultra, Quantel) operates at a maximum pulse energy of $50 \mathrm{~mJ}$, pulse duration of 8 $\mathrm{ns}$, and a repetition rate of $20 \mathrm{~Hz}$. The other one (Brilliant, Quantel) operates at a maximum pulse energy of $180 \mathrm{~mJ}$, pulse duration of $4 \mathrm{~ns}$, and a repetition rate of $10 \mathrm{~Hz}$. The laser beams were directed to the sample surface using the minimum number of optical components to avoid loss of power from the lasers. The plasma emission was collected using a telescope system composed of two Si plano-convex spherical lenses. An optical fiber was placed just before the focal point of the telescope to ensure the maximum efficiency of collected light. For optical alignment, the optical fiber was put in XYZ positioning stages, allowing an adjustment with the precision of $1 \mu \mathrm{m}$.

Sediment samples were analyzed in triplicate using two different LIBS setups. The first setup was the SP LIBS system using the laser at $1064 \mathrm{~nm}$. The laser energy was fixed in $34 \mathrm{~mJ}$, the delay time was at $200 \mathrm{~ns}$, and the acquisition gate width was $20 \mu \mathrm{s}$. The second setup was the DP LIBS with crossed beam configuration. The first pulse was at $532 \mathrm{~nm}$, and the second was at 1064 $\mathrm{nm}$. The energy of the infrared laser $(1064 \mathrm{~nm})$ was $34 \mathrm{~mJ}$, and the other laser $(532 \mathrm{~nm})$ was 35 mJ. The delay time between pulses was $200 \mathrm{~ns}$, the delay time between the last pulse and acquisition was $200 \mathrm{~ns}$, and the acquisition gate width was $5 \mu$ s. In both setups, for each sample, 45 spectra were acquired from different regions of the pellet with the 10 pulses accumulation.

\subsection{Data analysis}

The simple linear regression was performed between TP concentration determined by ICP OES and the depth of the sediment core at each collection station to evaluate the P distribution along the sediment core. The spectra obtained with SP and DP LIBS were processed with software developed using Python programming language. Outliers were excluded using a scalar product between the average and each measured spectrum. The correlation coefficient between the intensity at each wavelength of the spectra and the $\mathrm{P}$ concentration determined by ICP OES was calculated. This evaluation helps to identify the best lines for modeling. The analytical calibration was constructed with $70 \%$ of the samples and validation with the $30 \%$ remaining. The samples from the calibration and validation sets were chosen at random. For the chosen $\mathrm{P}$ lines, a baseline correction was done. ${ }^{21}$ The area under the best wavelength emission line, obtained using the correlation graph, was integrated using the Lorentz function. The average area was calculated for each sample $(n=3)$. The limit of detection (LOD) was calculated according to Currie. $^{22}$

\section{Results and discussion}

\subsection{LIBS}

Fig. 3 shows two typical plasma emission spectra from 175 to $341 \mathrm{~nm}$ from sediment samples obtained with the SP (Fig.3a) and DP (Fig.3b) LIBS systems.

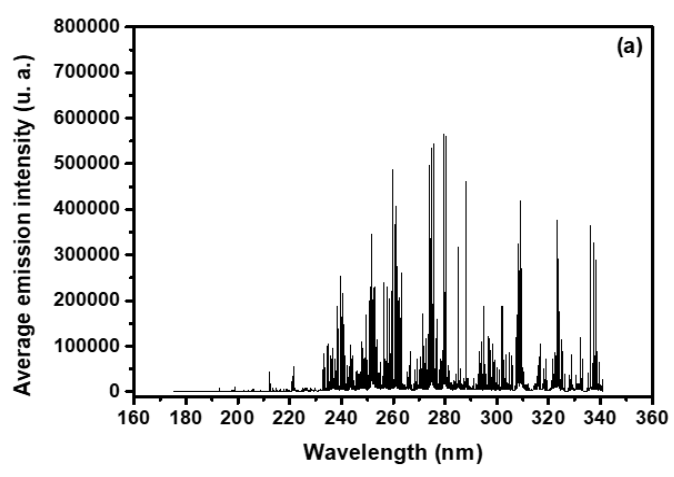




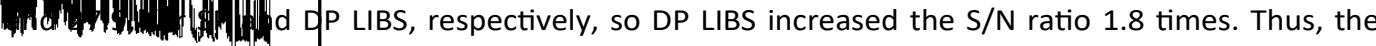
correlation between peak wake $_{a}$ fittheftmpy Lorentz function and reference values obtained with ICP OES (Fig.5a,b) for SP and DP LIBS. The $\mathrm{P}$ analytical calibration curves showed the existence of a strong linear correlation, in which Pearson's correlation coefFig. Emission spectrum of a sediment sample, BS, respectively, and a linear working range of $802-5770 \mathrm{mg} \mathrm{kg}{ }^{-1}$ of $P$ for from 175 to $341 \mathrm{~nm}$ obtained with the SP (a) and rr SP and DP LIBS, respectively, were calculated according to Currie. ${ }^{22}$ TheDP (a) LIBS systems. tion set (Fig. $5 \mathrm{c}, \mathrm{d})$. In this kind of validation, graphs were constructed using correlation of the $\mathrm{P}$ concentration predicted by the calibration models with the $\mathrm{P}$ concentration determined by ICP OES.

$\mathrm{P}$ (mg kg-1)

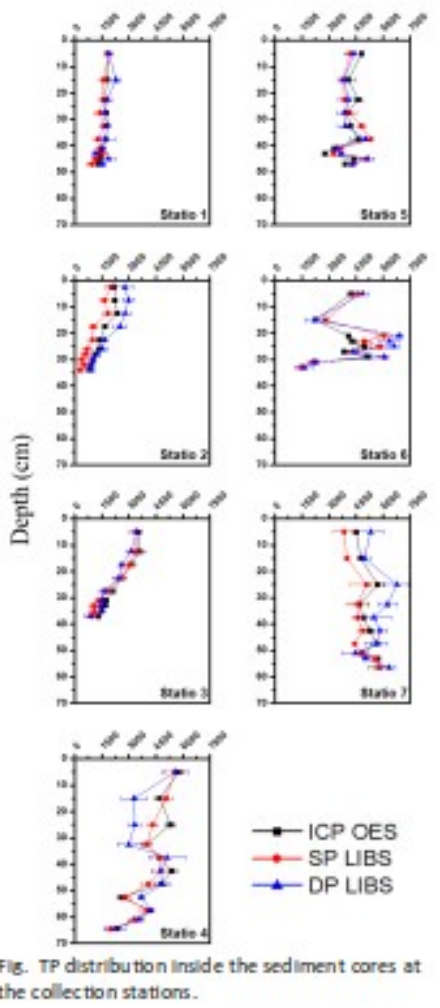

To better interpret the RMSEC (root mean squares error of calibration) and RMSEV (root mean squared error of validation) values, the average percentage error was calculated for the calibration and validation set in both methods. The percentage of average error for the calibration curves was $12 \%$ and $11 \%$ for SP and DP LIBS, respectively. For the validation curves, it was $14 \%$ and $10 \%$ for SP and DP LIBS, respectively. The mean errors in the quantification of TP by SP and DP LIBS is acceptable for measurements of samples without preparation, ${ }^{21}$ and although the matrix effect is common in the LIBS technique ${ }^{31}$, the models developed using the PI $214.91 \mathrm{~nm}$ line proved to be independent of the matrix and did not present non-linear effects. Additionally, in the chosen emission line, there is no interference from other elements present in the matrix, thus, allowing the construction of univariate calibration models for different types of samples ${ }^{32}$. The two methods developed for $P$ quantification in river sediments have LODs below the maximum natural level value $\left(750 \mathrm{mg} \mathrm{kg}^{-1}\right)$ defined by Brazilian laws ${ }^{29}$ and can be used to determine TP in the replacement of ICP OES. The method developed using DP LIBS is more sensitive and presented LOD two times smaller than the method using SP LIBS. However, to analyze the trophic level of eutrophic rivers, SP LIBS is sufficient and preferable, because it uses only one laser, therefore, being a cheaper system.
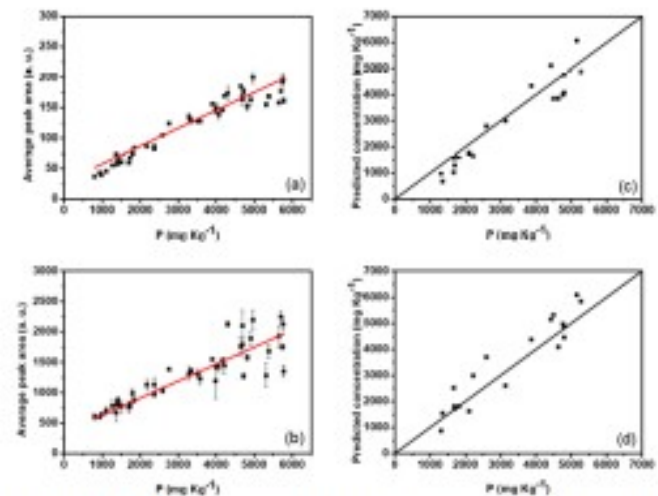

Fig. 5 Analytical cal bration curves for $P$ determination in sediment samples by (a) SP and (b) DP UBS and validation curves by (c) $S P$ and (d) DP UBS. 
The P concentration determined by ICP OES, SP and, DP LIBS was correlated with the depth of the sediment cores (Fig. 6). The P distribution in the sediment cores according to the developed LIBS methods showed the same behavior in all stations when compared with ICP OES. Therefore, both methods are very efficient to assess the degree of eutrophication and to obtain information about the anthropic contributions with regard to the $\mathrm{P}$ content in sediment cores.

The average concentration of TP in the sediments of the Tietê and Piracicaba rivers is high when compared with similar studies for eutrophic aquatic ecosystems. ${ }^{23-25}$ The highest $P$ concentration is at the top of the sediment core of station $4\left(5770 \mathrm{mg} \mathrm{kg}{ }^{-1}\right)$, this result is because the region of confluence between the rivers causes the immobilization of $P$ in the surface sediments. ${ }^{26}$ The collection points on the Piracicaba river (stations 1,2, and 3) and the confluence region (station 4) showed a significant decreasing linear trend of $P$ content with depth, with levels in the surface layers of $1846,2174,3506$, and $5770 \mathrm{mg} \mathrm{kg}{ }^{-1}$ of $P$, respectively. The values for the decrease rates of the $P$ content per centimeter were: $-14.9,-53.6,-66.4$, and $-66.7 \mathrm{mg} \mathrm{kg}^{-1} \mathrm{~cm}^{-1}$ with $r^{2}$ values corresponding to $0.87,0.98,0.99$, and 0.91 for stations $1,2,3$, and 4 , respectively. The increase in the TP content from the bottom to the top of the sediment core indicates that the deposition of $P$ is increasing, and this is due to the intensification of anthropogenic activities in the region ${ }^{27}$. Stations 5,6 , and 7 , in the Tietê river, do not show a significant linear trend, their average levels and corresponding standard deviations of $P$ content were: $4072 \pm 643,3629 \pm 1293$, and 5178 \pm 498 $\mathrm{mg} \mathrm{kg}^{-1}$ of $\mathrm{P}$, respectively. The difference in the behavior of the TP distribution along the profile in the Tiete (stations 5,6, and 7 ), and Piracicaba rivers (stations 1, 2, and 3), may be linked to the supply and resuspension of $P$ in the sediments. The main sources of $P$ at the sampled points are discharges from domestic sewage, with a large amount of fecal organic matter and detergents, water drained in agricultural areas, and some industrial effluents. ${ }^{28}$

According to Brazilian sediment quality criterion concerning the TP content, the deepest sediment layers of the Piracicaba river (stations 1, 2, and 3) are at the level that impacts the water body (TP concentration between 750 to $1500 \mathrm{mg} \mathrm{kg}^{-1}$ ), and the most superficial layers of the Piracicaba, all the sedimentary layers of the Tietê river (stations 5, 6, and 7), and the confluence region are at the level that causes a high impact on the water body (TP concentration above $1500 \mathrm{mg} \mathrm{kg}^{-1}$ ). ${ }^{29}$. These results indicate that the variability of TP in the vertical distribution is high for the Piracicaba river, while low in the Tietê river. The results presented in the Tietê river corroborate with those observed by Baran et. al in the Dunajec river, where there was no high $\mathrm{P}$ variability in the vertical distribution, this means that the intensely suspended matter transported by theses rivers have been homogeneous. ${ }^{30}$

\section{Conclusions}

SP and DP LIBS techniques proved to be a potential tool to determine TP in river sediments. The developed methods show a strong correlation ( $>0.91$ ) with the reference values, using univariate linear calibration. The method developed using DP LIBS is more sensitive, but the method using SP LIBS also demonstrated enough sensitivity for TP determination in eutrophic river sediments. The methods developed have the potential to be used by agencies responsible for preserving and restoring the quality of aquatic ecosystems by monitoring the TP content in sediment in these environments. Considering a high number of sampled points, the LIBS technique can be indicated, because it eliminates the use of reagents for sample preparation, reduces the time and cost of the analysis, and there is no generation of chemical residues. Therefore, we propose the use of LIBS techniques for monitoring of the large areas of rivers, in order to help the development of technologies, to avoid the entrance of $P$ in water bodies, for remediation of these ecosystems.

From ICP OES, SP and DP LIBS analysis a significant difference can be observed in the TP content of the sediment cores of the Piracicaba and Tietê rivers. The variability of TP in vertical distribution is greater in the Piracicaba river. These results suggest that the intensely suspended matter transported by the Piracicaba river was heterogeneous, while for the Tietê river it was homogeneous.

\section{Conflicts of interest}

There are no conflicts to declare.

\section{Acknowledgements}

This study was financed in part by the Coordenação de Aperfeiçoamento de Pessoal de Nível Superior - Brazil (CAPES) Finance Code 001. The authors thank CAPES (Grant 88882.331025/2019-01) for providing a fellowship to Carla Pereira de Morais, EMBRAPA Instrumentation and CEPOF (2013/07276-1) for financial support of this work, EMBRAPA Southeast Livestock and GAIA for the preparation and analysis of samples by ICP OES, and Bruno Ricardo Silva Costa for making the map with the geographical coordinates.

\section{References}


S. M. Thomaz, G. Pereira and T. A. Pagioro, Rev. brasleira Biol., 2001, 61, 277-286.

A. G. Ebadi and H. Hisoriev, Toxicol. Environ. Chem., 2018, 100, 540-549.

C. S. Reynolds and P. S. Davies, Biol. Rev., 2001, 76, 27-64.

N. Młynarczyk, M. Bartoszek, J. Polak and W. W. Sułkowski, Appl. Geochemistry, 2013, 37, 87-93.

U. S. Environmental Protection Agency, Method 6010C (SW-846): Inductively Coupled Plasma - Atomic Emission Spectrometry, 2000.

T. de S. Pereira, Í. T. A. Moreira, O. M. C. de Oliveira, M. C. Rios, W. A. C. S. Filho, M. de Almeida and G. C. de Carvalho, Mar. Pollut. Bull., 2015, 99, 166-177.

V. Rosolen, A. B. De-Campos, J. S. Govone and C. Rocha, Catena, 2015, 128, 203-210.

P. Anastas and N. Eghbali, Chem. Soc. Rev., 2010, 39, 301-312.

D. A. Cremers and L. J. Radziemski, Handbook of Laser-Induced Breakdown Spectroscopy, John Wiley \& Sons, U.K., 2013.

G. S. Senesi, L. Martin-Neto, P. R. Villas-Boas, G. Nicolodelli and D. M. B. P. Milori, J. Soils Sediments, 2018, 18, $1292-1302$.

E. C. Ferreira, D. M. B. P. Milori, E. J. Ferreira, L. M. E. Dos Santos, L. Martin-Neto and A. R. D. A. Nogueira, Talanta, 2011, 85, 435440.

G. Nicolodelli, G. S. Senesi, R. A. Romano, I. L. De Oliveira Perazzoli and D. M. B. P. Milori, Spectrochim. Acta Part B At. Spectrosc., 2015, 111, 23-29.

C. R. Menegatti, G. Nicolodelli, G. S. Senesi, O. A. da Silva, H. J. I. Filho, P. R. Villas Boas, B. S. Marangoni and D. M. B. P. Milori, Appl. Opt., 2017, 56, 3730-3735.

G. Nicolodelli, G. S. Senesi, A. C. Ranulfi, B. S. Marangoni, A. Watanabe, V. de Melo Benites, P. P. A. de Oliveira, P. Villas-Boas and D. M. B. P. Milori, Microchem. J., 2017, 133, 272-278.

R. Barbini, F. Colao, V. Lazic, R. Fantoni, A. Palucci and M. Angelone, Spectrochim. Acta Part B At. Spectrosc., 2002, 57, 1203-1218. V. Lazic, R. Barbini, F. Colao, R. Fantoni and A. Palucci, Spectrochim. Acta Part B At. Spectrosc., 2001, 56, 807-820.

E. S. Austria, E. M. Fuentes, G. M. Nuesca and R. B. Lamorena, Spectrochim. Acta Part B At. Spectrosc., 2017, 136, 1-7.

F. M. Aprile and M. Bouvy, Brazilian J. Aquat. Sci. Technol., 2008, 12, 1-8.

J. Bramorski and S. M. Villela, Rev. Ciências Ambient., 2014, 8, 61-70.

D. I. T. Favaro, F. R. Rocha, M. Angelini, H. R. A Henriques, J. S. Soares, P. S. C. Silva and S. M. B. Oliveira, J. Radioanal. Nucl. Chem., 2018, 316, 805-818.

B. S. Marangoni, K. S. G. Silva, G. Nicolodelli, G. S. Senesi, J. S. Cabral, P. R. Villas-Boas, C. S. Silva, P. C. Teixeira, A. R. A. Nogueira, V. M. Benites and D. M. B. P. Milori, Anal. Methods, 2016, 8, 78-82.

L. A. Currie, Anal. Chim. Acta, 1999, 391, 105-126.

S. K. Barik, S. Bramha, T. K. Bastia, D. Behera, P. K. Mohanty and P. Rath, Int. J. Sediment Res., 2019, 34, 251-261.

S. Wen, H. Wang, T. Wu, J. Yang, X. Jiang and J. Zhong, Sci. Total Environ., 2020, 704, 1-10.

S. Chen, Y. Chen, J. Liu, J. Zhang and A. Wu, Procedia Environ. Sci., 2011, 10, 1797-1801.

S. Yuan, H. Tang, Y. Xiao, Y. Xia, C. Melching and Z. Li, J. Hydrol., 2019, 573, 568-580.

C. M. Lupinacci, F. T. da Conceição, A. L. Heck Simon and A. Perez Filho, Earth Surf. Process. Landforms, 2017, 42, $2402-2413$. W. S. Smith, E. L. G. Espíndola and O. Rocha, Acta Limnol. Bras., 2014, 26, 73-88.

CETESB, https://cetesb.sp.gov.br/aguas-interiores/wp-content/uploads/sites/12/2018/06/Relat\%C3\%B3rio-de-Qualidade-das\%C3\%81guas-Interiores-no-Estado-de-S\%C3\%A3o-Paulo-2017.pdf, accessed September 2018.

A. Baran, M. Tarnawski, T. Koniarz and M. Szara, Environ. Geochem. Health, 2019, 41, 2929-2948.

J. Hou, L. Zhang, Y. Zhao, Z. Wang, Y. Zhang, W. Ma, L. Dong, W. Yin, L. Xiao and S. Jia, Plasma Sci. Technol., 2019, 21, 034016.

A. Lima, T. Varão, F. Schiavon, I. De Sousa, G. Saverio, D. Santos, E. Cristina, J. Anchieta and G. Neto, 2018, 139, $322-326$. 